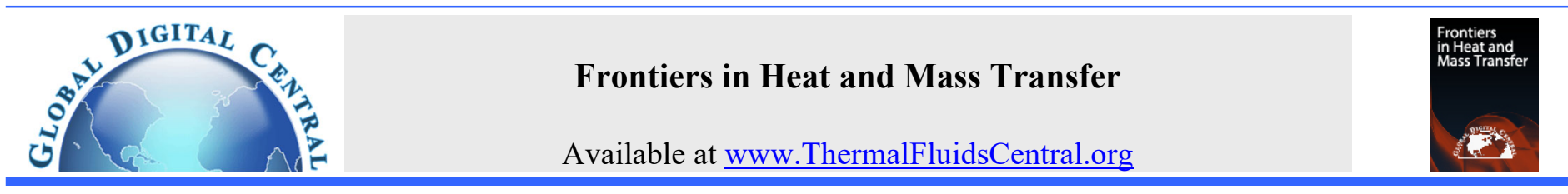

\title{
PERFORMANCE EVALUATION OF A SOLAR WATER HEATER INTEGRATED WITH BUILT-IN THERMAL ENERGY STORAGE VIA POROUS MEDIA
}

\author{
Hasan S. Majdi ${ }^{a,}{ }^{*}$, Azher M. Abed ${ }^{b}$, Laith J. Habeeb ${ }^{c}$ \\ ${ }^{a}$ Department of Chemical Engineering and Petroleum Industries, Al-Mustaqbal University College Babylon, 51001, Iraq \\ ${ }^{b}$ Air conditioning and Refrigeration Techniques Engineering Department, Al-Mustaqbal University College, Babylon, 51001, Iraq \\ ${ }^{c}$ Training and Workshop Center, University of Technology - Iraq, Baghdad, 10001, Iraq
}

\begin{abstract}
The present work presents and analyzes the results acquired from outdoor experimental measurements of a solar latent heat storage unit integrated with built-in thermal energy storage at the presence and absence of porous media. The tank consists of a porous media part, a packed of glass beds, and the fluid flowing through the void space surrounding the porous glass beds. The porous tanks were filled by $1.68 \mathrm{~mm}$ glass beds to form bed heights (h) of 10 and $20 \mathrm{~cm}$. Results show that the maximum thermal storage of $110 \mathrm{~min}$ is achieved in hot flow rate $\mathrm{qh}=4 \mathrm{LPM}$, cold flow rate $\mathrm{qc}=5 \mathrm{LPM}$ and $\mathrm{h}=20$ $\mathrm{cm}$, while the same flow rates of the case of absence porous media gives $90 \mathrm{~min}$ of thermal storage time. The same enhancement was achieved in case of $\mathrm{qh}=2 \mathrm{LPM}, \mathrm{qc}=2 \mathrm{LPM}$ and $\mathrm{h}=20 \mathrm{~cm}$ during heating process due to heat transfer resistance by mean of porous media.
\end{abstract}

Keywords: Thermal storage tank, Evacuated tube solar collector, Porous media.

\section{INTRODUCTION}

Effective utilization of time-dependent energy resources relies on appropriate energy storage methods to reduce the time and rate mismatch between supply and demand. Thermal energy storages (TESs) provide a high degree of flexibility. Since a variety of energy sources such as solar heat, industrial waste heat, heat pumps and off-peak electricity can be utilized, either combined or separately. In particular, solar energy applications require a large energy storage capacity in order to cover a minimum of 1-2 days demand. As the solar radiation is a time-dependent energy source Nallusamy et al., 2007; Khalifa et al, 2013; Bouadila et al., 2014). The progresses in the solar thermal regimes have caused it feasible to perform a heat source with a high temperature from the solar irradiation. Such heat with a high is required to be reserved to perform a dispatchable power (Malan et al., 2015). The electricity high cost and impacts of environment have encouraged searching for alternatives of power supply. That result a decrease of the great impact of environment that the present generation of power owns. The cost of storage of thermal energy is too less. That makes the solar thermal method too interested for power generation in large scale (Alva et al., 2017). Evacuated tube type solar collector is the common design of thermal energy generator by utilizing solar radiation. A number of experimental and numerical studies have been performed to improve the performance. They was used PCM as heat storage to enhanced the solar thermal system efficiency (Lee et al., 2006; Nallusamy et al., 2007; Khalifa et al., 2013; Bouadila et al., 2014; Malan et al., 2015; Gopi, 2017). Recently, a number of studied numerically packed bed heat storage system using spherical capsules filled with three kinds of phase change material (PCM) connected with a flat plate solar collector. The results indicated that this new type heat storage packed bed has higher energy and exergy transfer efficiencies than the traditional packed bed. In addition, the average energy and exergy collection efficiency of its solar collector are higher too. Thermal energy can be stored in the form of latent heat by using suitable phase change materials (PCMs). Such as inorganic PCM, organic PCM and organic-inorganic PCM, which can offer high storage capacity per unit volume and per unit mass (Al-Kayiem and Lin, 2014). Another way to improve the heat storage medium is by using porous media. The heat transfer in porous media, plays important role in various industrial process, petroleum refinery and building construction (Sankar et al., 2011). A conjugate heat transfer by using porous media promotes insulation and thermal energy storage at laminar conditions while turbulence eddies are developed at turbulent conditions (Zhao et al., 2020). The heat storage tank problems are related to heat transfer characteristics of heat storage tank; the convective action is the major effective mechanism in heat storage work principles. The free and forced convection may be presented at the same time, which called mixed convection. For example, the heated body in an unbounded domain. Actually, both free convection and forced convection actions occur at the same time so that one may be necessary to resolve which is major. On the other hand, this attraction should be resisted since natural convection rarely plays the more essential role in the design, operation performance of some heat transferring or equipment in industrial and local uses (Theodore, 2011), (Mohammadnejad and Hossainpour, 2020) (Hu et al., 2021).

In general, the convective heat transfer depends mainly upon parameters. Such as: heat flux, temperature gradient, object shape, geometry, body size, fluid density, fluid viscosity, fluid heat capacity, fluid thermal conductivity, fluid orientation (vertical or horizontal) and the inclination of object (Pop and Ingham, 2001). In porous media, the porosity and permeability are induced to the affected parameters on natural convection heat transfer (Badruddin et al., 2012). Moreover, any change in temperature or heat flux of surfaces, gives a change in properties values, which leads to fluid vortex motion. This effect is noticed as streamlines expression and isothermal lines instead of thermal boundary layer expression, which is used forced convection. The mechanism of free convection can be varied if the surfaces are heated isothermally or by constant heat flux (Yousef et al., 1982) and (Xuan and $\mathrm{Li}, 2000)$. In exacting, the configuration of internal flow is highly intricate than the configuration of external flow (Abdulkadhim et al., 
2019; Majdi et al., 2019; Abdulkadhim et al., 2020). The problems of external flow are modeled by utilizing the hypothesis of traditional boundary layer via the assumption that the boundary layer exterior area is unchanged via the solid boundary (Das et al., 2017). In comparison, for the configuration of internal convection, the connections between the core and boundary layer comprise a main intricacy in the problem of natural convection (Samarskii et al., 1993; Abdulkadhim et al., 2018; Majdi et al., 2020). For domestic use, materials with melting temperature between 40 and $80{ }^{\circ} \mathrm{C}$ are commonly studied, with paraffins, fatty acids, salt hydrates and alcohols being the most popular. For harvesting the solar radiation, usually flat plate or evacuated tubes solar collectors are used, either commercial ones or modified (Eleni et al., 2021). An extensive review has been made with regard to various control strategies applied to PCM-enhanced buildings. Such as ON/OFF control, conventional control methods (classical control, optimal, adaptive, and predictive control) and intelligent controls (Gohar and Mohammed, 2021).

The objective of the present work is to investigate the possibility of enhancing the performance of an evacuated solar collector for water heating by using TES. With an emphasis on the effect of the porous media martials at different operation conditions such as hot water flow rates, cold-water flow rates and bed height during daytime.

\section{Material And Methods}

The next two subsection explain the theoretical and experimental description. Theoretical side talked about models or formulation, and mathematical equations related to porous media, whereas experimental work explain the overall setup of the experiments in the laboratory (full description of the system).

\subsection{Mathematical Models}

The porous media models for single phase flows and multiphase flows use the Superficial Velocity Porous Formulation as the default. ANSYS Fluent calculates the superficial phase or mixture velocities based on the volumetric flow rate in a porous region. The porous media model is described in the following sections for single phase flow, however, it is important to note the following for multiphase flow:

- In the Eulerian multiphase model, the general porous media modeling approach, physical laws, and equations described below are applied to the corresponding phase for mass continuity, momentum, energy, and all the other scalar equations.

- The Superficial Velocity Porous Formulation generally gives good representations of the bulk pressure loss through a porous region. However, since the superficial velocity values within a porous region remain the same as those outside the porous region, it cannot predict the velocity increase in porous zones and therefore limits the accuracy of the model.

Porous media are modeled by the addition of a momentum source term to the standard fluid flow equations. The source term is composed of two parts: a viscous loss term (Darcy, the first term on the right-hand side of Equation 1, and an inertial loss term (the second term on the righthand side of Equation 1)

$$
S_{i}=\left(\sum_{j u=1}^{3} D_{i j} \mu v_{i}+\sum_{j=1}^{3} C_{i j} \frac{1}{2} \rho|v| v_{j}\right)
$$

Where $S_{i}$ is the source term for the $i$ th $(x, y$, or $z)$ momentum equation, $|v|$ is the magnitude of the velocity and $D$ and $C$ are prescribed matrices. This momentum sink contributes to the pressure gradient in the porous cell, creating a pressure drop that is proportional to the fluid velocity (or velocity squared) in the cell.

To recover the case of simple homogeneous porous media $S_{i}=-\left(\frac{\mu}{\alpha} v_{i}+C_{2} \frac{1}{2} \rho|v| v_{i}\right)$ where $\alpha$ is the permeability and $C_{2}$ is the inertial resistance factor, simply specify $D$ and $C$ as diagonal matrices with $1 / \alpha$ and $C_{2}$, respectively, on the diagonals (and zero for the other elements).

ANSYS Fluent also allows the source term to be modeled as a power law of the velocity magnitude:

$$
S_{i}=-C_{o}|v|^{C_{i}}=-C_{D}|v|^{\left(C_{1}-1\right)} v_{i}
$$

where $C_{0}$ and $C_{l}$ are user-defined empirical coefficients.

Important: In the power-law model, the pressure drop is isotropic and the units for $C_{0}$ are SI.

- $\quad$ Energy Equation (Equilibrium Thermal Model) in Porous Media

For simulations in which the porous medium and fluid flow are assumed to be in thermal equilibrium, the conduction flux in the porous medium uses an effective conductivity and the transient term includes the thermal inertia of the solid region on the medium:

$\frac{\partial}{\partial t}\left(\gamma \rho_{f E_{f}}+(1-\gamma) \rho_{s} E_{s}\right)+\nabla \cdot\left(\vec{v}\left(\rho_{f} E_{f}+p\right)\right)=S_{f}^{h}+\nabla \cdot\left[K_{e f f} \nabla T-\right.$

$\left.\left(\sum_{i} h_{i} J_{i}\right)+(\vec{\tau} \cdot \vec{v})\right]$

The effective thermal conductivity in the porous medium, $k_{e f f}$, is computed by ANSYS Fluent as the volume average of the fluid conductivity and the solid conductivity.

$K_{e f f}=\gamma K_{f}+(1-\gamma) K_{s}$

Where:

$k_{f} \quad=$ fluid phase thermal conductivity (including the turbulent contribution, $k_{t}$ )

$k_{s} \quad=$ solid medium thermal conductivity

The fluid thermal conductivity $k_{f}$ and the solid thermal conductivity $k_{s}$ can be computed via user-defined functions.

The anisotropic effective thermal conductivity can also be specified via user-defined functions. In this case, the isotropic contributions from the fluid, $\gamma k f$, are added to the diagonal elements of the solid anisotropic thermal conductivity matrix.

\subsection{Experimental Setup And Procedures}

The experimental work was studied in Al-Mustaqbal University College renewable energies lab. / Iraq- Babylon/ Al-Hilla city in May- July 2019. The rig configuration is illustrated in figure 1 . The experimental setup consisted of thermosyphon type water heating system, porous media tank, pumping system, data logger and water tank. The thermosyphon type (solar heater system) consisted of $150 \mathrm{~L}$ tank and 15 collector absorber tube of $1.68 \mathrm{~m}$ length and 2.38 in diameter. A storage tank is integrated with collector box made of $0.5 \mathrm{~mm}$ thick of steel. The porous media tank dimensions were $55 \mathrm{~cm}$ length, $34 \mathrm{~cm}$ width and $20 \mathrm{~cm}$ height. A pump is placed in the cycle to circulate the flow from the upper tank of solar collector to the porous media tank. The pump is a GrundfosUPS series with $0.05 \mathrm{~kW}$ power and maximum flow rate of $3.27 \mathrm{~m}^{3} / \mathrm{h}$. A bypass line is used to controlling the flow rate. The data logger was used to measure the temperature of porous media tank with and without glass beds packages for the morning to afternoon periods. The porous medium that filled the test section is glass beds with geometric specification: 1.68 $\mathrm{mm}$ glass beds to form bed heights of 10 and $20 \mathrm{~cm}$. TSP with and without porous media is the parameter of performance evaluation.

The minimum value of the irradiance normal to sun is $790 \mathrm{~W} / \mathrm{m} 2$ and its diffusion part must be lower than $20 \%$. The test performed from 9:00 Am to 1:00 Pm with time interval around $15 \mathrm{~min}$ and the solar radiation was optimum 12:00 pm for May, June and July. The water was heated by solar collector from 8:00 to 9:00 am to keep the water at $50^{\circ} \mathrm{C}$ inside the upper tank of solar collector. The pump was operated at (9:00 
am) to (1:00 pm); and the solar radiation was optimum 12:00 pm for May, June and July in Al-Hilla city. From 1:00 to 2:00 pm, the cold water from the water tank was delivered to solar collector at $41{ }^{\circ} \mathrm{C}$, which is the ambient temperature in the shadow. The hot flow rates were 2, 4 and 6 LPM. The cold flow rates were 2 and 5 LPM. The used pump had a maximum flow rate of 7 LPM.

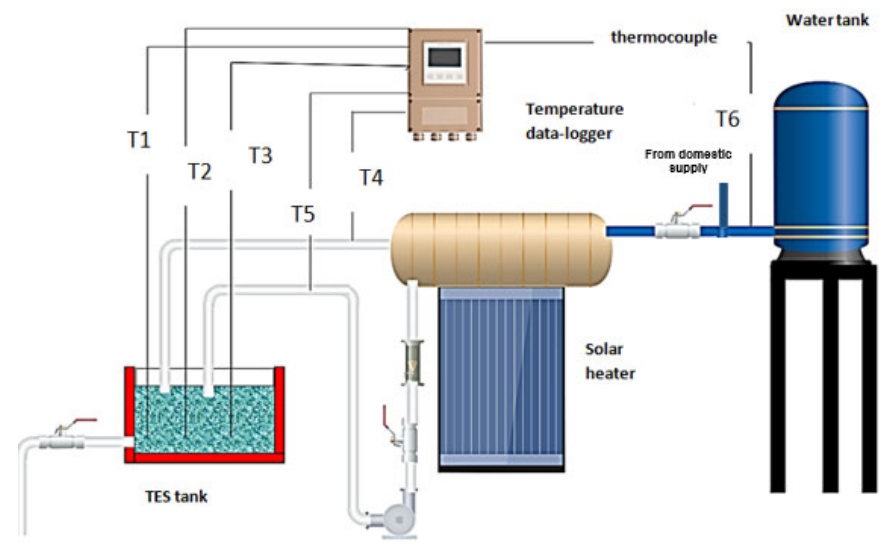

Fig. 1 The experimental setup of present work.

The analytical solution was performed during this investigation by modeling the energy balance through the porous media tank. The basic assumptions leading are a one-dimensional plug flow, no axial conduction or dispersion, constant properties, no mass transfer, no heat loss to the environment, and no temperature gradients within the solid particles.

Inlet heat - outlet heat $=$ accumulated heat

The energy storage capacity of a water (or other liquid) storage unit at uniform temperature (i.e. fully mixed or no stratified) operating over a finite temperature difference is given as equation (7)

$Q=m C p \Delta T$

Where $\mathrm{Q}$ is the total heat capacity for a cycle operating through the temperature range $\Delta \mathrm{T}$, and $\mathrm{m}$ and $\mathrm{Cp}$ are the mass and the specific heat, respectively, of fluid in the unit. The temperature ranges over which such a unit can operate is limited at the lower extreme for most applications by the requirements of the process. An energy balance on the no stratified tank is as (8):

$$
\dot{m} C p\left(T_{\text {in }}-T_{\text {out }}\right)=M C p \frac{d T_{\text {out }}}{d t}
$$

Where $t$ is the time

Solving for the tank temperature at the end of a time increment using the boundary conditions

Tout $=\mathrm{Ta}$ at $\mathrm{t}=\mathrm{ta}$ and Tout $=\mathrm{Tb}$ at $\mathrm{t}=\mathrm{tb}$

Where ta is the start time, tb is the finish time.

After arranging and solving of the qn. (9), it gets:

$\frac{\left(T_{\text {in }}-T_{a}\right)}{\left(T_{\text {in }}-T_{b}\right)}=\exp \left(\frac{\dot{m}}{M}\left(t_{a}-t_{b}\right)\right)$

The last expression is applicable for heating and cooling during the experimental period. Tout was close to the mean temperature of the porous tank T1, T2 and T3. "Eqs." may be used in the middle of a sentence. At the beginning of a sentence, "Equations (1) and (2) are ..." must be used.

When any abbreviations or acronyms are used for the first time, they must be defined. For example, dual-phase lag model (DPL) is widely used in descriptions of microscale heat transfer.

\section{RESULTS AND DISCUSSION}

The experimental results of thermal storage energy system of solar evacuated tube collector have been presented. The radiation flux has been also measured for completely experimental period. As shown in Fig. 2, the radiation behavior has uniform behavior but with different magnitude from 9:00 am to 2:00 pm. The radiation flux rate increases by increasing the time for whole day and become constant at the maximum value of radiation rate, at the beginning, the time zero min. there is no radiation flux, increases the utilization portion of phase change material in the process, smooths the outlet temperature of the heat transfer fluid and reduces the melting time. The maximum range of solar radiation is observed in July 2019 and minimum radiation rate is observed during May, which is the present investigation period in Al-Hilla city. period months in 2019 in Al-Hilla city.

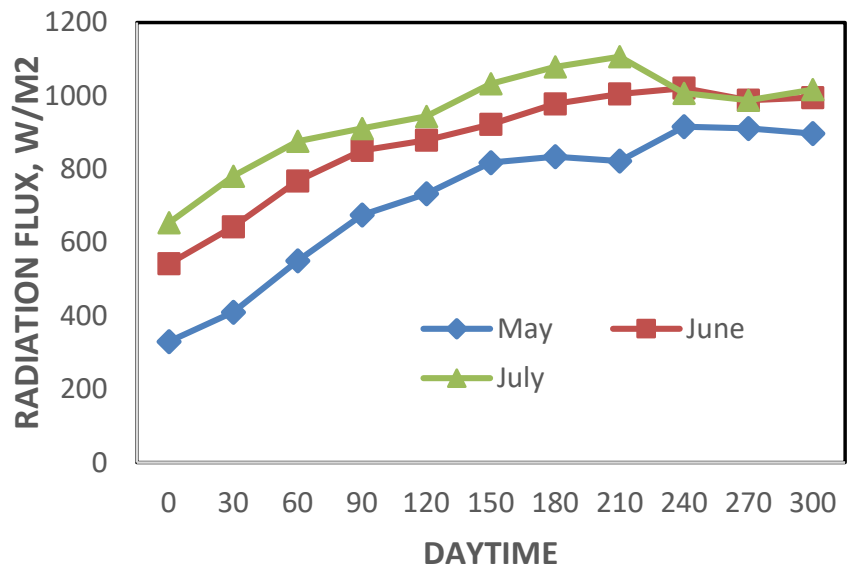

Fig. 2 Radiation flux vs. early daytime for the investigation

Figures 3, 4 from 9:00 am to 2:00 pm and 5 from 9:00 am to 01:00 pm show the temperatures inside the outside tank vs. early daytime for various hot and cold flow rates in absence of porous glass beds. The temperatures of heated water (T1, T2 and T3) and the temperature of inlet stream to tank (T4) increasing by increasing early daytime because of the continuous providing of solar flux to heater collector, which supplied the hot water to heat storage tank. The general behavior of pumping hot water to TES tank by action of circulating is subjected to forces and free convection actions, this behavior is called free stream mixed convection. After maximum temperature recovery $\left(55-65^{\circ} \mathrm{C}\right)$, the temperature drop is achieved by auction of pumping cold water $\left(38-42^{\circ} \mathrm{C}\right)$. The effect of cold flow rate $q_{c}$ has inverse proportion to storage time (at $q_{c}=2 \mathrm{LPM}, t s=25$ min while $q_{c}=5 \mathrm{LPM}, t_{s}=75-90 \mathrm{~min}$ ). The most convent reason of this behavior, the higher flow rates promotes higher contact time which tends to achieve thermal equilibrium as soon as, and vice versa.

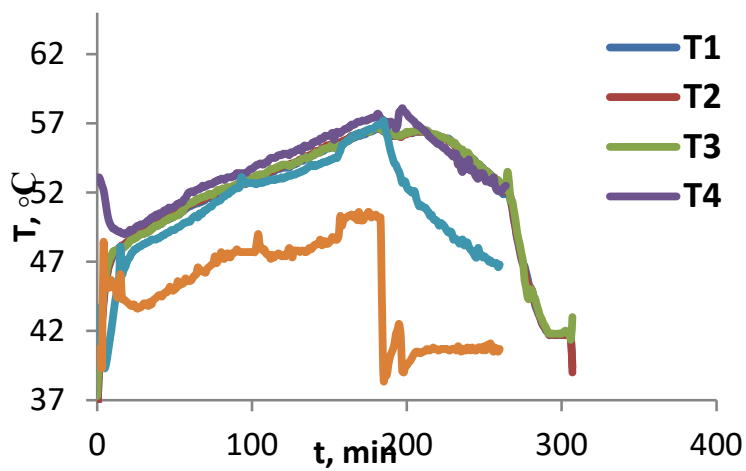

Fig. 3 Temperature vs. time of thermal storage system $\mathrm{qh}=6 \mathrm{LPM}$ and $\mathrm{qc}=5 \mathrm{LPM}$. 


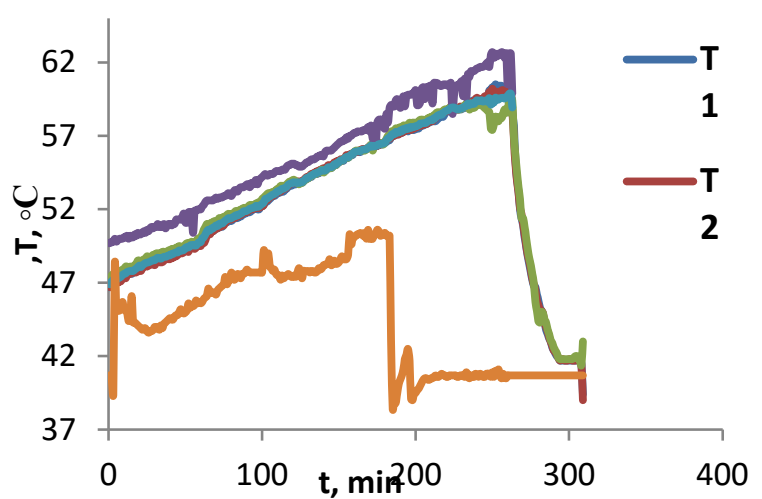

Fig. 4 Temperature vs. time of thermal storage system $q_{h}=2 \mathrm{LPM}$ and $q_{c}=2$ LPM

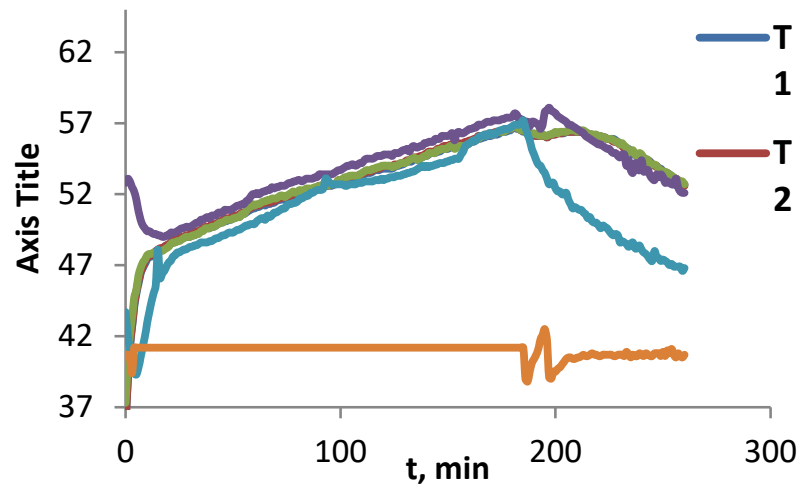

Fig. 5 Temperature vs. time of thermal storage system $q h=4 \mathrm{LPM}$ and $q c=5$ LPM

Figures 6, 7 from 9:00 am to 11:30 pm and 8 from 9:00 am to 12:00 pm indicate the complex behavior of presence porous media on TES tank in which the bed height of $10 \mathrm{~cm}$ was used. At qc $=2 \mathrm{LPM}$, thermal storage time becomes 35 min while sharp drop in temperature is observed at qc $=5$ LPM. The minimum package height promotes turbulent level in higher cold flow rate which the cooling heat transfer is achieved quickly. From the literatures, the increasing of turbulent level promotes higher thermal contact time. The same behavior was observed for various $q_{h}$. The interaction between porous media height and the flow rates of cold and hot streams makes the investigation complexity. The another reason of sharp behavior of temperature in case of higher cold flow rates is the presence of porous media decreases the volume of fluid inside TES tank.

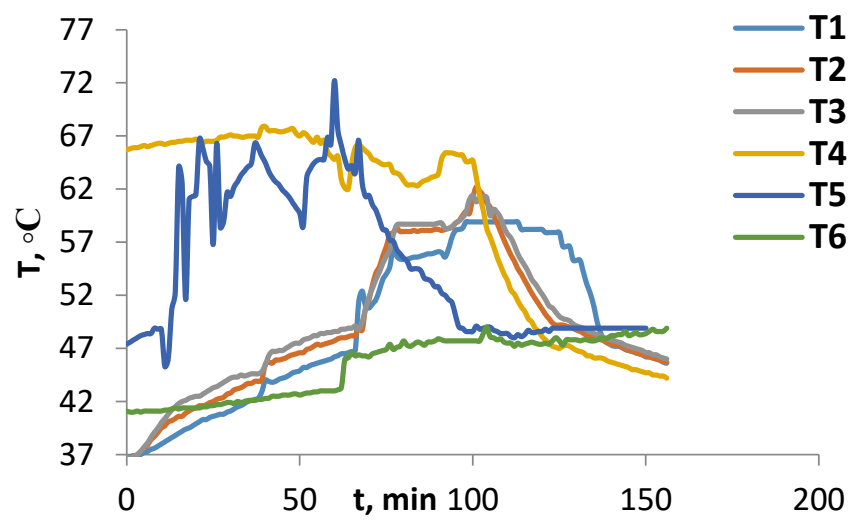

Fig. 6 Temperature vs. time of thermal storage system $\mathrm{qh}=6$ $\mathrm{LPM}$ and $\mathrm{qc}=5 \mathrm{LPM}$ and $\mathrm{h}=10 \mathrm{~cm}$.

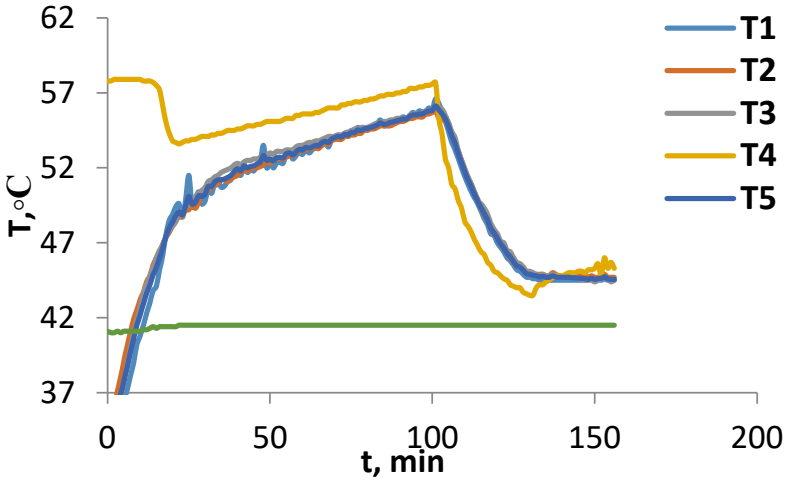

Fig. 7 Temperature vs. time of thermal storage system $\mathrm{qh}=2 \mathrm{LPM}$ and $\mathrm{qc}=2$

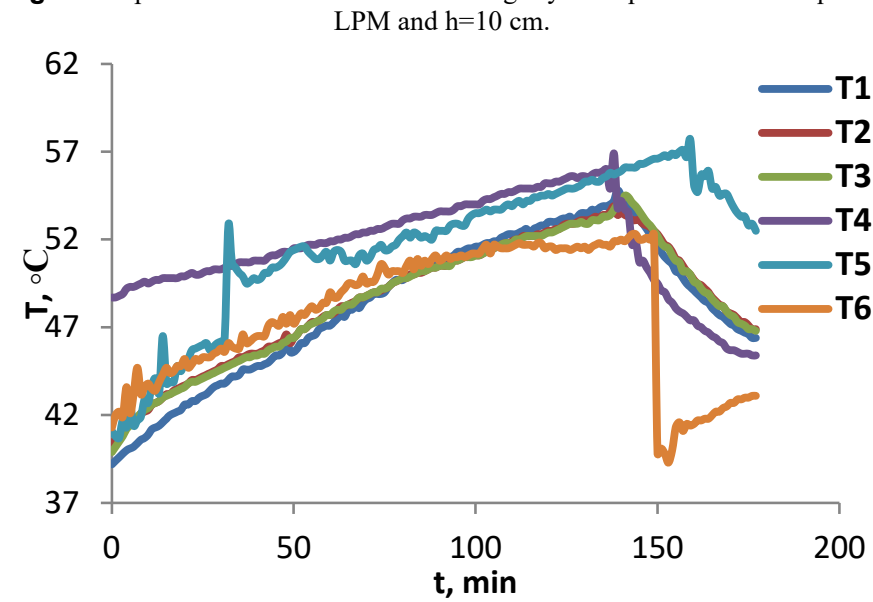

Fig. 8 Temperature vs. time of thermal storage system $\mathrm{qh}=4 \mathrm{LPM}$ and $\mathrm{qc}=5$ $\mathrm{LPM}$ and $\mathrm{h}=10 \mathrm{~cm}$.

In figures 9, 10 from 9:00 am to 12:00 pm and 11 from 9:00 am to 11:30 pm, the different behaviors are presented by utilizing $20 \mathrm{~cm}$ bed height. The thermal storage time is limited by the hot flow rate qh unlike $10 \mathrm{~cm}$ case. The bed height of $20 \mathrm{~cm}$ promotes higher thermal resistance for $\mathrm{qh}=2$ and 6 LPM which promotes sluggish behavior in case of 2 LPM. The highest thermal storage time was achieved at $\mathrm{qh}=4 \mathrm{LPM}$ and $\mathrm{qc}=6 \mathrm{LPM}$ by value of $110 \mathrm{~min}$. This behavior indicates that the lower hot flow rate of 2 LPM gives higher contact time due to heat transfer residence time. The increasing of fluid flow rate reduces the heat transfer radiance time especially in heat exchanging process. While higher hot flow rate of 6 LPM has sharp decreasing in storage time due to higher flow rate with low fluid volume inside TES tank.

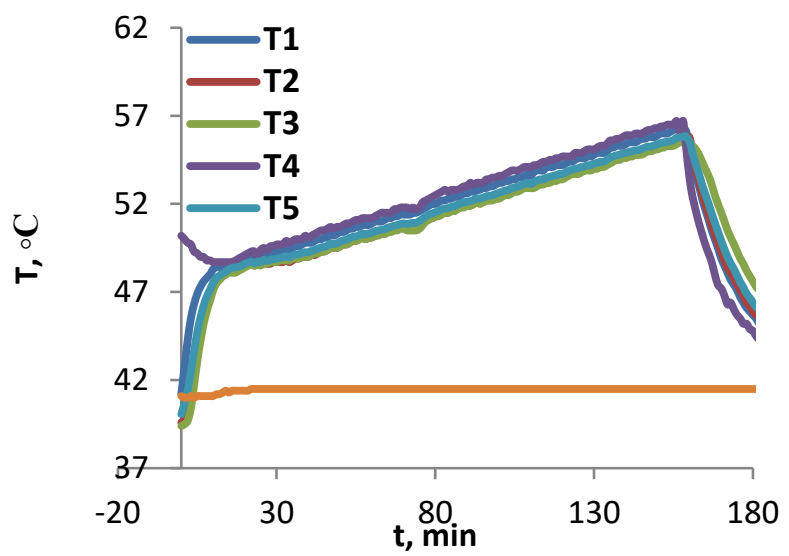

Fig. 9 Temperature vs. time of thermal storage system $\mathrm{qh}=6 \mathrm{LP} \mathrm{M}$ and $\mathrm{qc}=5$ $\mathrm{LPM}$ and $\mathrm{h}=20 \mathrm{~cm}$. 


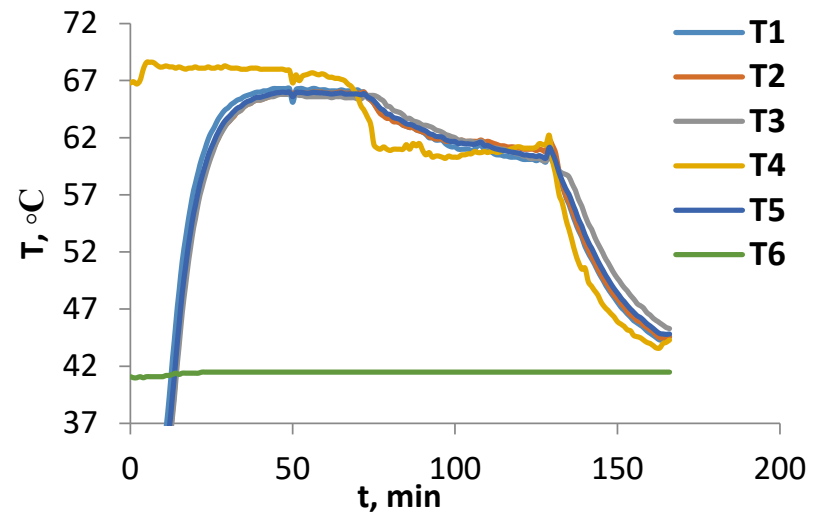

Fig. 10 Temperature vs. time of thermal storage system $\mathrm{qhc}=2 \mathrm{LPM}$ and $\mathrm{qc}=2$ LPM and $\mathrm{h}=20 \mathrm{~cm}$.

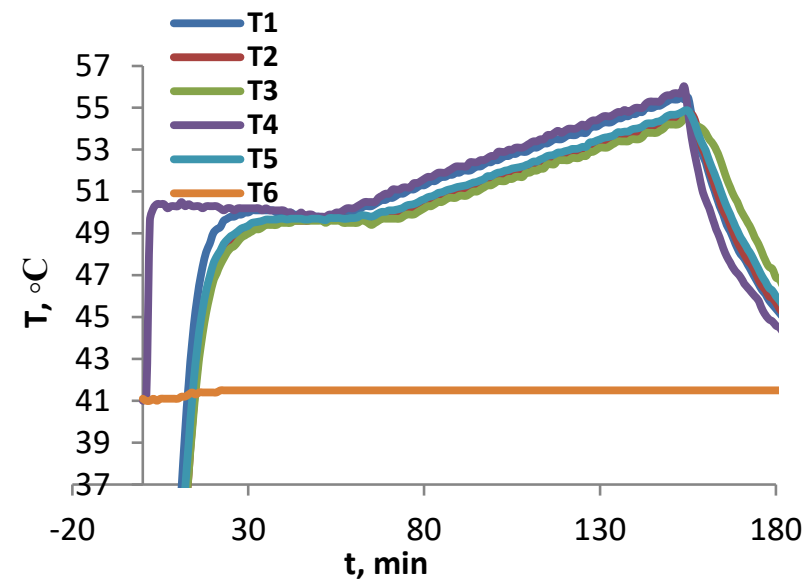

Fig. 11 Temperature vs. time of thermal storage system $\mathrm{q}_{\mathrm{h}}=4 \mathrm{LPM}$ and $\mathrm{q}_{\mathrm{c}}=5 \mathrm{LPM}$ and $\mathrm{h}=20 \mathrm{~cm}$.

\section{a) without porous media, $\%$}

$\mathrm{Qc}=5 \mathrm{LPM}, \mathrm{Qh}=4 \mathrm{LPM}$

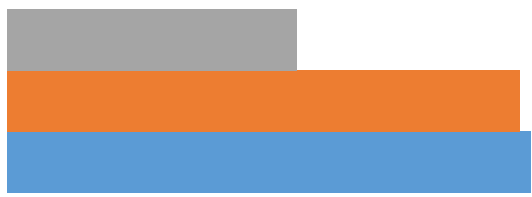

Qc=5LPM, Qh=6 LPM

Qc=2LPM, Qh=2 LPM

0

0.1

0.2

0.3

0.4

\section{b) with $10 \mathrm{~cm}$ bed, \%}

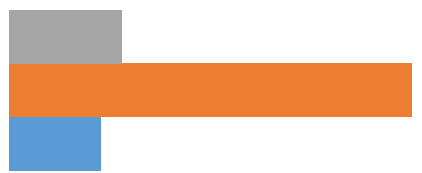

Qc=5LPM, Qh=4 LPM

$\mathrm{Q} \mathrm{c}=5 \mathrm{LPM}, \mathrm{Qh}=6 \mathrm{LPM}$

- $\mathrm{Qc}=2 \mathrm{LPM}, \mathrm{Qh}=2 \mathrm{LPM}$

\section{(c) with $20 \mathrm{~cm}$ bed, \%}

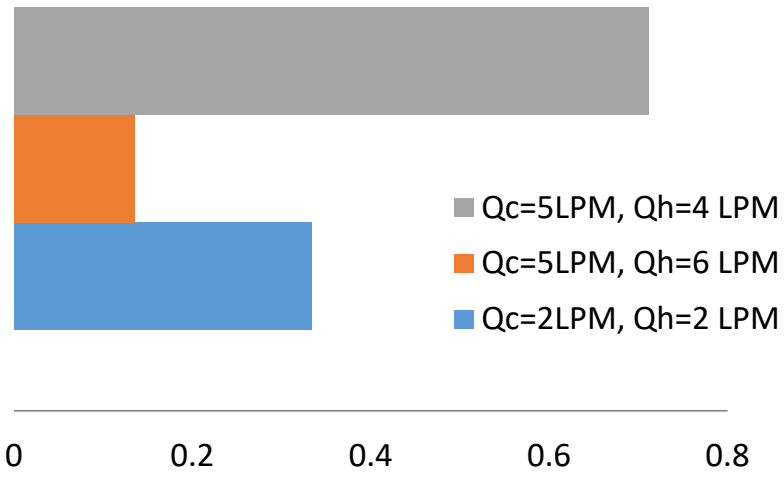

Fig. 12 ( $a, b \& c)$ The offset percentage between the experimental and numerical solution of modeling.

The numerical analysis has been presented by ANSYS Fluent. Figure 13 shows the change of temperature of water with time in the two cases, on the right side, case without porous media, and on the left side, case with porous media. We can notice that the maximum thermal storage can be reached at temperature $323.2 \mathrm{~K}$ with time $90 \mathrm{~min}$. in the case of absence porous media, whereas the maximum thermal storage can be reached at temperature $323.1 \mathrm{~K}$ with time $110 \mathrm{~min}$. in the case of presence of porous media. The difference of time between two cases $(20$ min.) due to the nature of porous because water passes through the core of porous causes delay in the time to reach the super thermal storage.

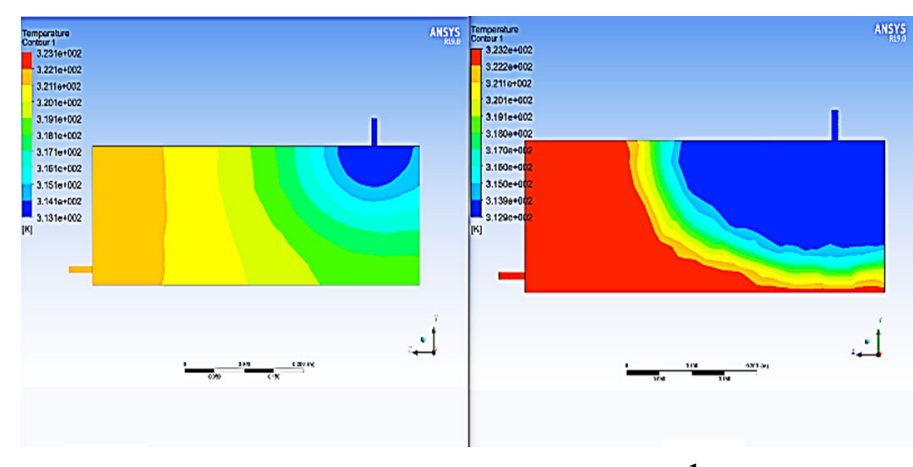

a

b

Fig. 13 The temperature distribution in cases a) with porous media and b) without porous media.

Figure 14 shows how velocity of water changes from maximum value $0.539 \mathrm{~m} / \mathrm{s}$ to $0 \mathrm{~m} / \mathrm{s}$ in the case of absence porous media.

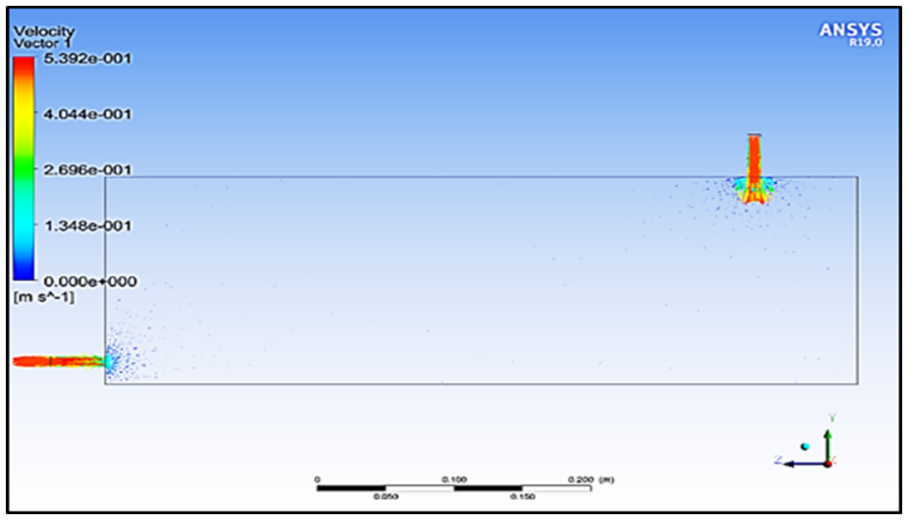

Fig. 14 The velocity distribution of water 
Finally, the numerical analysis indicates the good validation between experimental work and theoretical solution of equation (4) which is represented in equation (5). The offset percentage increase with presence of porous media and continue to increase for limited level of porous media, after this level, the percentage tend to decrease. The maximum offset is $1.17 \%$ in case of $\mathrm{qh}=6 \mathrm{LPM}$, $\mathrm{qc}=5 \mathrm{LPM}$ and $\mathrm{h}=$ $10 \mathrm{~cm}$ as shown in figures 12 . This corresponding validation promotes high confident level of the present investigation toward the equation of the same systems.

\section{CONCLUSION}

The experimental study of thermal storage performance of thermal energy storage was investigated. The present work discussed the relation between thermal contact time and thermal storage time. This connection can be seen by observing the effect of flow rates of cooling and heating processes and the height of porous bed, as:

1- $\quad$ The maximum thermal storage $(110 \mathrm{~min})$ is achieved in $\mathrm{qh}=4$ $\mathrm{LPM}, \mathrm{qc}=5 \mathrm{LPM}$ and $\mathrm{h}=20 \mathrm{~cm}$, while the same flow rates of the case of absence porous media gives $90 \mathrm{~min}$ of thermal storage time.

2- $\quad$ The heat storage same enhancement was achieved in case of $\mathrm{qh}=2 \mathrm{LPM}, \mathrm{qc}=2 \mathrm{LPM}$ and $20 \mathrm{~cm}$ bed height during heating process due to heat transfer resistance by mean of porous media (sluggish behavior).

3- The theoretical solution and analysis promotes the rich validity between the experimental work and numerical solution of PDE that describe the equation of present system.

\section{ACKNOWLEDGEMENTS}

The authors would like to sincerely thank the Al-Mustaqbal University College for the provision of the grant to support this work.

\section{NOMENCLATURE}

$\begin{array}{ll}C & \text { heat capacity }\left(\mathrm{J} / \mathrm{m}^{3} \cdot \mathrm{K}\right) \\ c_{p} & \text { specific heat }(\mathrm{J} / \mathrm{kg} \cdot \mathrm{K}) \\ h & \text { porous media height }(\mathrm{cm}) \\ k & \text { thermal conductivity }(\mathrm{W} / \mathrm{m} \cdot \mathrm{K}) \\ M & \text { water mass inside } \mathrm{TES} \text { tank }(\mathrm{kg}) \\ \dot{m} & \text { mass flow rates }(\mathrm{kg} / \mathrm{s}) \\ q^{\prime \prime} & \text { heat flux }\left(\mathrm{W} / \mathrm{m}^{2}\right) \\ q_{h} & \text { hot stream flow rate }(\mathrm{LPM}) \\ q_{c} & \text { cold stream flow rate }(\mathrm{LPM}) \\ t & \text { time }(\mathrm{s}) \\ T & \text { temperature }\left({ }^{\circ} \mathrm{C}\right) \\ \mathrm{T} 1, \mathrm{~T} 2 \text { and } & \text { T3 températures Inside TES tank }\left({ }^{\circ} \mathrm{C}\right) \\ \mathrm{T} 4 \text { and T5 } & \text { TES tank inlet and outlet temperature }\left({ }^{\circ} \mathrm{C}\right) \\ \mathrm{T} 6 & \text { cold water inlet temperature }\left({ }^{\circ} \mathrm{C}\right) \\ E_{f} & \text { total fluid energy } \\ \text { Es } & \text { total solid medium energy } \\ \mathrm{keff} & \text { effective thermal conductivity of the medium } \\ \text { Shf } & \text { fluid enthalpy source term } \\ G r e e k & \text { Symbols } \\ \gamma & \text { porosity of the medium } \\ \varepsilon & \text { total emissivity } \\ \rho & \text { density }\left(\mathrm{kg} / \mathrm{m}^{3}\right) \\ \rho_{f} & \text { fluid density } \\ \rho_{s} & \text { solid medium density }\end{array}$

\section{REFERENCES}

Abdulkadhim A., Hamzah H. K., Ali F. H., Abed A. M. and Abed I. M. (2019). "Natural convection among inner corrugated cylinders inside wavy enclosure filled with nanofluid superposed in porous-nanofluid layers." International Communications in Heat and Mass Transfer 109: 104350

http://doi.org/10.1016/j.icheatmasstransfer.2019.104350

Abdulkadhim A., Hamzah H. K., Ali F. H., Yıldız Ç., Abed A. M., Abed E. M. and Aric1 M. (2020). "Effect of heat generation and heat absorption on natural convection of $\mathrm{Cu}$-water nanofluid in a wavy enclosure under magnetic field." International Communications in Heat and Mass Transfer: 105024.

https://doi.org/10.1016/j.icheatmasstransfer.2020.105024

Abdulkadhim A., Majdi H. S. and Abed A. (2018). "Characteristics of natural convection flow and heat transfer of parallelogramic enclosure with an inner circular cylinder using liquid nanofluids." Frontiers in Heat and Mass Transfer (FHMT) 12.

http://dx.doi.org/10.18280/mmep.060416

Al-Kayiem H. H., and Lin S. C. (2014). "Performance evaluation of a solar water heater integrated with a PCM nanocomposite TES at various inclinations." Solar Energy 109: 82-92.

https://doi.org/10.1016/j.solener.2014.08.021

Alva G., Liu L., Huang X. and Fang G. (2017). "Thermal energy storage materials and systems for solar energy applications." Renewable and Sustainable Energy Reviews 68: 693-706.

https://doi.org/ 10.1016/j.rser.2016.10.021

Badruddin I. A., Al-Rashed A. A., Ahmed N. S., Kamangar S. and Jeevan K. (2012). "Natural convection in a square porous annulus." International Journal of Heat and Mass Transfer 55 (23-24): 7175-7187. https://doi.org/10.1016/j.ijheatmasstransfer.2012.07.034

Bouadila S., Fteïti M., Oueslati M. M., Guizani A. and Farhat A. (2014). "Enhancement of latent heat storage in a rectangular cavity: Solar water heater case study." Energy conversion and management 78: 904-912. http://dx.doi.org/10.1016/j.enconman.2013.07.094

Das D., Roy M. and Basak T. (2017). "Studies on natural convection within enclosures of various (non-square) shapes-A review." International Journal of Heat and Mass Transfer 106: 356-406. https://doi.org/10.1016/J.IJHEAT MASS TRANSFER.2016.08.034

Gopi R. (2017). "Experimental investigation of flat plate collector with cylindrical fins in a solar air heater." J Indus Pollut Control 33(2): 11281131.

https://doi.org/10.1016/j.inpa.2018.07.004

Hu N., Li Z. R., R. H. Zhang, J. Liu and L. W. Fan (2021). "An Experimental Investigation of Constrained Melting Heat Transfer of Nano-Enhanced Phase Change Materials in a Horizontal Cylindrical Capsule Using Thermochromic Liquid Crystal Thermography." Journal of Heat Transfer 143(1). https://doi.org/10.1115/1.4048471

Khalifa A. J., Suffer K. H. and Mahmoud M. S. (2013). "A storage domestic solar hot water system with a back layer of phase change material." Experimental Thermal and Fluid Science 44: 174-181. https://doi.org/10.1016/j.expthermflusci.2012.05.017

Lee W. S., Chen B. R. and Chen S. L. (2006). "Latent heat storage in a two-phase thermosyphon solar water heater." 
https://doi.org/10.1115/1.2147588

Majdi H. S., Abdulkadhim A. and Abed A. (2019). "Numerical investigation of natural convection heat transfer in a parallelogramic enclosure having an inner circular cylinder using liquid nanofluid." Frointers Heat Mass Transf 12(2). https://doi.org/10.5098/hmt.12.2

Majdi H. S., Abdulkadhim A. and Abed A. M. (2020). "Computational Fluid Dynamics Investigation of Buoyancy Driven Flow Between Circular Body and Wavy Enclosure Filled with Nanofluid/Porous Medium" International Journal of Heat and Technology 38(2): 403-417. https://doi.org/10.18280/ijht.380216

Malan D. R., Dobson and Dinter F. (2015). "Solar thermal energy storage in power generation using phase change material with heat pipes and fins to enhance heat transfer."_Energy Procedia 69: 925-936.

https://doi.org/10.1016/j.egypro.2015.03.176

Mohammadnejad F. and Hossainpour S. (2020). "A CFD modeling and investigation of a packed bed of high temperature phase change materials (PCMs) with different layer configurations." Journal of Energy Storage 28: 101209.

https://doi.org/10.1016/j.est.2020.101209

Nallusamy N. S., Sampath and Velraj R. (2007). "Experimental investigation on a combined sensible and latent heat storage system integrated with constant/varying (solar) heat sources." Renewable energy 32(7): 1206-1227.

https://doi.org/10.1016/j.renene.2006.04.015

Pop I., and Ingham D. B. (2001). Convective heat transfer: mathematical and computational modelling of viscous fluids and porous media, Elsevier.

\section{https://lib.ugent.be/catalog/ebk01:1000000000384362}

Samarskii A., Vabishchevich P., Iliev O., and Churbanov A. (1993). "Numerical simulation of convection/diffusion phase change problems-

a review." International journal of heat and mass transfer 36 (17): 40954106.

https://dx.doi.org/10.1016/0017-9310(93)90071-D

Sankar M., Park Y., Lopez J. and DoY . (2011). "Numerical study of natural convection in a vertical porous annulus with discrete heating." International Journal of Heat and Mass Transfer 54(7-8): 1493-1505. https://doi.org/10.1016/j.ijheatmasstransfer.2010.11.043

Theodore L. (2011). "Heat transfer applications for the practicing engineer", John Wiley \& Sons. https://doi.org/10.1002/9780470937228

Xuan Y. and Li Q. (2000). "Heat transfer enhancement of nanofluids." International Journal of heat and fluid flow 21(1): 58-64. https://doi.org/10.1016/S0142-727X(99)00067-3

Yousef W., Tarasuk J., and McKeen W. (1982). "Free convection heat transfer from upward-facing isothermal horizontal surfaces." https://doi.org/10.1115/1.3245120

Zhao X., Jiaqiang E., Zhang Z., Chen J., Liao G., Zhang F., Leng E., Han D. and Hu W. (2020). "A review on heat enhancement in thermal energy conversion and management using Field Synergy Principle." Applied Energy 257: 113995.

https://doi.org/10.1016/j.apenergy.2019.113995 